\title{
Generalized latent inhibition in taste-aversion learning
}

\author{
ROGER M. TARPY and STEPHEN M. McINTOSH \\ Bucknell University, Lewisburg, Pennsylvania 17837
}

\begin{abstract}
Rats were preexposed, over 9 days, to either nine different flavors or a single flavor. Then they were given a novel saccharin-lithium pairing (controls were injected with isotonic saline). Generalized latent inhibition was demonstrated in the multiflavor group: Learned aversion to the novel saccharin CS was very transient. One-flavor subjects, in contrast, demonstrated a strong and lasting aversion to saccharin.
\end{abstract}

Latent inhibition, the retardation of conditioning following CS preexposure, has been demonstrated many times in conventional classical conditioning studies (see Lubow, 1973) as well as in taste-aversion experiments (e.g., Ahlers \& Best, 1971; Kalat \& Rozin, 1970). In addition, generalized latent inhibition, the retardation of later conditioning to a novel CS that was similar to the preexposed $\mathrm{CS}$, has been considered in the context of conventional classical conditioning paradigms (e.g., Siegel, 1969) and in a taste-aversion paradigm. For example, Capretta, Petersik, and Stewart (1975), Siegel (1974), and Braveman and Jarvis (Note 1) all found that preexposure to one flavor (or several flavors) produced an increased consumption of a novel flavor. For two of these studies (Capretta et al., 1975; Siegel, 1974) it may be presumed that such a reduction in neophobia would have been accompanied by a reduction in aversion learning had taste-aversion procedures been followed. Braveman and Jarvis (Note 1, Experiment 1B), however, failed to confirm such a presumption. In their study, neophobia for a target CS was reduced by preexposure to several other flavors but aversion learning was undiminished. Therefore, those authors reasoned that latent inhibition had not generalized, that is, aversive learning was retarded only when the subjects were preexposed to the actual target CS.

We have reexamined the issue of generalized latent inhibition because the evidence for whether nonspecific CS preexposure retards later conditioning is still very conflicting. For example, Braveman and Jarvis (Note 1, Experiment 1A) found that preexposure to four flavors did, in fact, retard aversive learning to a fifth target CS. Moreover, they used a relatively insensitive (Grote \& Brown, 1971) one-bottle test to assess generalized latent

This experiment was part of an MA thesis by Stephen M. McIntosh; a preliminary report of the data was given at the Eastern Psychological Association meetings, New York, April 1976. The authors thank L. Pfister, D. Candland, O. Floody, and A. Leshner for their helpful comments on an earlier draft of the paper. Reprints may be obtained from Roger M. Tarpy, Department of Psychology, Bucknell University, Lewisburg, Pennsylvania 17837. inhibition and only four flavors during preexposure. Therefore, Braveman and Jarvis' acceptance of the null hypothesis (p. 7) does not appear warranted.

In our study, rats received preexposure to either nine different flavors or a single flavor prior to a novel saccharin-lithium pairing. Saccharin aversion was later tested using a two-bottle procedure.

\section{METHOD}

\section{Subjects}

The subjects were 37 Sprague-Dawley female rats with weights ranging from about 200 to $300 \mathrm{~g}$. They were housed individually in wire-mesh cages and had ad-lib access to food throughout the experiment. All testing was done at about 11:00 a.m. during the light portion of the cycle.

\section{Procedure}

Subjects were water deprived and were given 24 sessions. All sessions used one bottle, except for the two-bottle choice test on Day 24, and all fluids were at room temperature. On Days 113, water was available to each animal on the right front of the home cage and a baseline drinking regimen was established. Sessions 1-5 lasted $20 \mathrm{~min}$, while all remaining drinking sessions were $10 \mathrm{~min}$.

Differential treatment began on Session 14. Group 9-LiCl $(n=10)$ received a different flavor on each of the next nine sessions. On Day 23, these subjects were given access to saccharin (which was never presented prior to that session) and, immediately, an injection of lithium chloride (i.p., $10 \mathrm{ml} / \mathrm{kg}, .15-\mathrm{M}$ concentration). Group 9-Sal $(n=9)$ was treated in the same way except that those subjects received an injection of isotonic saline following saccharin exposure on the training day. All of the nine flavors were randomly presented to the subjects of these two groups; that is, each subject received all nine flavors but the order of presentation was randomized across subjects. The following flavors were used: $.9 \% \mathrm{NaCl}(\mathrm{w} / \mathrm{v}), .1 \%$ imitation vanilla extract, $.1 \%$ anise extract, $.1 \%$ spearmint extract, . $1 \%$ mocha extract ( $\mathrm{v} / \mathrm{v}$, all extracts were Wagner's), .4\% grape Kool-Aid (w/v unsweetened), $.4 \%$ orange Kool-Aid (w/v unsweetened), $1 \%$ Sanka decaffineated coffee (w/v), and skim milk.

Subjects in Group 1- $\mathrm{LiCl}(\mathrm{n}=9)$ received only a single flavor during the nine sessions (Days 14-22). Each of the flavors cited above was represented, that is, one subject was given only Sanka, another anise, and so forth. On the training day (Session 23), this group was given a novel saccharin flavor and an injection of lithium chloride. Group 1-Sal $(n=9)$ was treated 


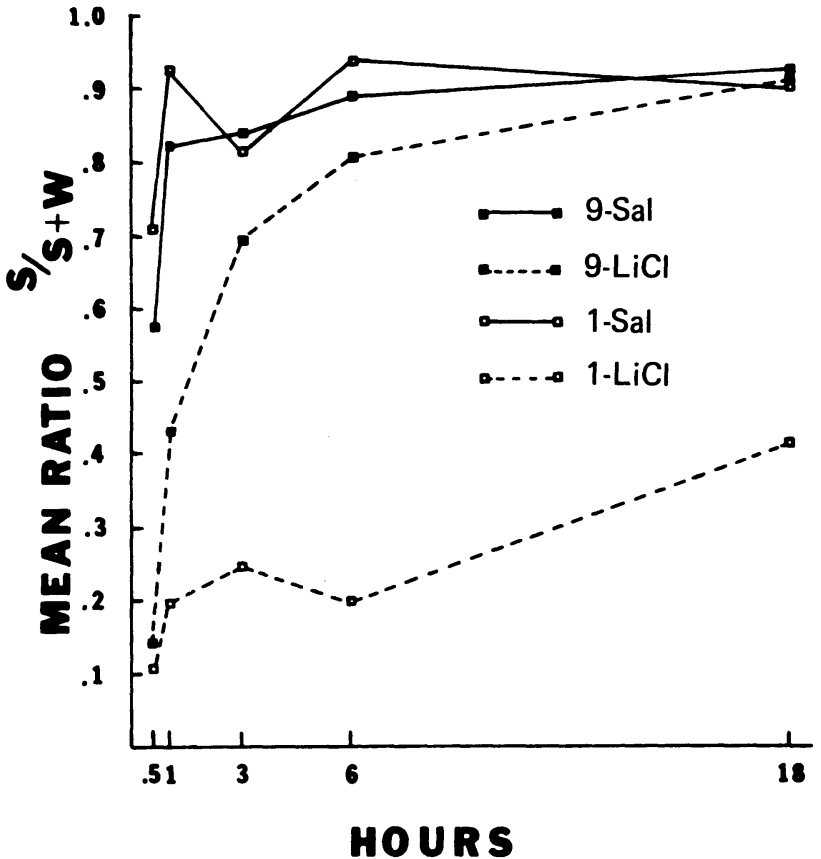

Figure 1. Mean suppression ratio (saccharin to total consumption) on the five test periods.

identically except that they received a saline injection on the training day.

On Day 24, all subjects were given a two-bottle choice between saccharin and water (water placed on the left side). Fluid consumption was measured at $.5,1,3,6$, and $18 \mathrm{~h}$, and the relative amount of saccharin consumed for each time period (saccharin to total fluid intake) was computed. Thus, the experiment was a 2 by 2 by 5 design with multiple- vs. single-flavor preexposure, lithium chloride vs. placebo injection, and measurement periods as the factors.

\section{RESULTS AND DISCUSSION}

As illustrated in Figure 1, the main effect of preexposure treatment (i.e., one vs. nine flavors) on subsequent preference ratios was highly significant $[F(1,33)=$ $8.2, \mathrm{p}<.01 \mathrm{l}$, as were the main effects of the 18 -h test period $[\mathrm{F}(4,132)=22.9, \mathrm{p}<.01]$ and the $\mathrm{LiCl}$ vs. saline injection $[F(1,33)=58.4, p<.001]$. The interaction of Preexposure Treatment by Test Periods was significant $[F(4,132)=5.3, p<.01]$, as were the Preexposure Treatment by Injection $[\mathrm{F}(1,33)=14.2$, $\mathrm{p}<.01]$ and Injection by Test Period $[\mathrm{F}(4,132)=3.7$, $\mathrm{p}<.01]$ interactions. The two control groups (1-Sal and 9-Sal) exhibited relatively strong and equal preferences for saccharin, whereas Group $1-\mathrm{LiCl}$ acquired an aversion to saccharin which persisted throughout the test periods. The most interesting finding concerned the performance of Group 9-LiCl. Those subjects exhibited an aversion during the first hour of testing (relative to their 9-Sal controls) but the ratio increased markedly after that time. In fact, comparisons using Sheffés procedure showed that Groups 9- $\mathrm{LiCl}$ and 9-Sal never differed statistically. Group 9-LiCl did not differ significantly from $1-\mathrm{LiCl}$ on the first three measurement periods but did thereafter $(\mathrm{p}<.05)$. In summary, the experiment demonstrated a strong and lasting saccharin aversion in those subjects that were preexposed to only one other flavor. A transient aversion, however, occurred in the $9-\mathrm{LiCl}$ animals that were preexposed to nine flavors.

It is interesting to note the effect of preexposure on neophobia. The multiple-flavor procedure produced a significant increase in consumption from the last preexposure day to the training session. Mean consumption for the combined nine-flavor groups was 12.8 and $13.2 \mathrm{ml}$ on those two sessions, respectively ( $p<.01$, Wilcoxon test). Although the average increase in consumption for all one-flavor subjects was somewhat higher (a mean change from 13.0 to $13.9 \mathrm{ml}$ ), the difference was not significant $(.1>p<.05)$. These results essentially replicate what has been found by other investigators (e.g., Braveman \& Jarvis, Note 1).

The present results confirm previous studies that showed that multiple-flavor preexposure reduces neophobia for a novel target CS. However, unlike Experiment 1B by Braveman and Jarvis (Note 1), the present study found that multiple-flavor preexposure also retarded aversion learning. In other words, latent inhibition generalized from the nine different flavors to the novel target CS and caused a reduction in conditioning to that CS. Although suppression was observed in the 9- $\mathrm{LiCl}$ group, it was transient compared to the strong and lasting aversion demonstrated in Group 1-LiCl.

A number of procedures may account for the difference between our results and those of Braveman and Jarvis (Note 1). First, we used a more sensitive (e.g., Grote \& Brown, 1971) two-bottle test of aversion. Second, we used a larger number of flavors in our multiflavor preexposure group. Presumably, generalized latent inhibition summated over several of the flavors (this must be assumed since the one-flavor subjects did not demonstrate latent inhibition); having more flavors provided a greater chance for generalized latent inhibition to summate. Regardless of the mechanism, the present study clearly showed that generalized latent inhibition can occur when a sufficient number of preexposure flavors are used.

Although additional research is needed before a full and adequate theory of these results is possible, we believe that these findings also can be discussed in terms of relative CS novelty. This claim is consistent with a number of investigators (e.g., Braveman, 1975; Kalat, 1974) who have shown that CS salience is a function of relative novelty. In one important paper, Lubow, Rifkin, and Alek (1976) demonstrated that conditioning depended on the degree to which the CS stood out from the environmental context. Similarly, in our study, 
conditioning to saccharin may have been retarded in Group 9- $\mathrm{LiCl}$ because the saccharin did not stand out from the environment; it was merely another novel flavor within the context of many novel flavors. Thus, contextual, or relative, novelty of any given CS may be enhanced through habituation to a constant environment (e.g., Mitchell, Kirschbaum, \& Perry, 1975; McIntosh \& Tarpy, 1977) or decreased through exposure to a changing and novel environment (present study). In the former case, conditioning is improved because the discriminability of the CS from its context is increased; in the latter case, conditioning is retarded because the CS is less discriminable as a unique event. The authors are in the process of testing this notion.

\section{REFERENCE NOTE}

1. Bravemen, N. S., \& Jarvis, P. S. Independence of neophobia and aversion formation: Implications for learned safety. Paper presented at the 17 th annual convention of the Psychonomic Society. St. Louis, 1976.

\section{REFERENCES}

Ahlers, R. H.. \& Best. P. J. Novelty vs. temporal contiguity in learned taste aversions. Psychonomic Science, 1971, 25. 34-36.

Braveman. N. S. Relative salience of gustatory and visual cues in the formation of poison-based food aversions by guinea pigs (Cavia porcellus). Behavioral Biology, 1975, 14. 189-199.
Capretta, P. J.. Peterik, T. T., \& Stewart, D. J. Acceptance of novel tlavor is increased after early experiences of dive se tastes. Nature, 1975, 254. 689-694.

Grote. F. W.. \& Brown. R. T. Conditioned taste aversions: Two-stimulus iests are more sensitive than one-stimulus tests. Behavior Reseurch Methods \& Instrumentation, 1971. 3. $311-312$.

KALAT, J. W. Taste salience depends on novelty, not concentration, in taste-aversion learning in the rat. Journal of Comparative and Physiological Psychology. 1974. 86, 47-50.

Kalat, J. W., \& Rozin, P. "Salience": A factor which can override temporal contiguity in taste-aversion learning. Journal of Comparative and Physiological Psychology, 1970, 71, 192-197.

Lubow. R. E. Latent inhibition. Psychological Builetin. 1973. 79. 398-407.

Lubow, R. E., Rifkin, B.. \& Alek, M. The context effect: The relationship between stimulus preexposure and environmental preexposure determines subsequent learning. Journal of Experimental Psychology: Animal Behavior Processes, 1976, 2. 38-47.

MCINTOSH, S. M.. \& TARPY, R. M. Retention of latent inhibition in a taste-aversion paradigm. Bulletin of the Psychonomic Society, 1977. 9, 411-412.

Mitchell, D.. Kirschbaum, E. H., \& Perry, R. L. Effects of neophobia and habituation on the poison-induced avoidance of exteroceptive stimuli in the rat. Journal of Experimental Psychology: Animal Behavior Processes, 1975, 1, 47-55.

SIEGEl, S. Generalization of latent inhibition. Journal of Comparative and Physiological Psychology, 1969, 69, 157-159."

SIEGEL. S. Flavor preexposure and "learned safety." Journal of Comparative and Physiological Psychology, 1974, 87, 1073-1082.

(Received for publication June 28, 1977.) 